\title{
Adaptation to sustained high plasma vasopressin in water and electrolyte homeostasis in the rat transgenic for the metallothionein-vasopressin fusion gene
}

\author{
H Yokoi, H Nagasaki, K Tachikawa, H Arima, T Murase, Y Miura, \\ M Hirabayashi ${ }^{1}$ and $\mathbf{Y}$ Oiso \\ First Department of Internal Medicine, Nagoya University School of Medicine, 65 Tsurumai-cho, Showa-ku, Nagoya 466-8550, Japan \\ ${ }^{1}$ YS New Technology Institute Inc., 519 Shimoishibashi, Ishibashi-machi, Shimotsuga-gun, Tochigi 329-0512, Japan \\ (Requests for offprints should be addressed to H Yokoi; Email: yokoi-ngy@umin.u-tokyo.ac.jp)
}

\begin{abstract}
Prolonged exposure of tissues to a receptor agonist often leads to adaptive changes that limit the subsequent responsiveness of the tissue to the same agonist. Recently, we have generated rats transgenic for the metallothionein I-human arginine vasopressin (AVP) fusion gene (Tg), which produced high plasma AVP with relatively preserved renal water excretion, suggesting that there might be adaptive mechanism(s) for maintaining water and electrolyte homeostasis against chronic AVP oversecretion from the earliest stage of life. In this study, to investigate whether down-regulation of AVP V2 receptor (V2R), which could possibly be caused by long-standing high plasma AVP, participates in this adaptive mechanism(s), non-peptidic V2R antagonist OPC31260 was administered to reverse the down-regulation, and water loading was performed after V2R antagonist treatment had been withdrawn. Additionally, to confirm the down-regulation, Northern blotting analysis for V2R mRNA was carried out. Tg rats showed slightly decreased urine volume and water intake with an equivalent plasma $\left[\mathrm{Na}^{+}\right]$level $(\mathrm{Tg}$
\end{abstract}

$140 \cdot 4 \pm 0.6 \mathrm{mEq} / \mathrm{l}$; control $139 \cdot 3 \pm 0.6 \mathrm{mEq} / \mathrm{l}$ ) under basal conditions. After water loading using a liquid diet containing zinc, which stimulates the promoter region in the transgene, the urine increase showed only limited suppression with a dramatically increased plasma AVP level and mild hyponatremia $(135.8 \pm 1.8 \mathrm{mEq} / \mathrm{l})$ in $\mathrm{Tg}$ rats. When diet containing OPC31260 had been provided for 4 days until the day before the start of water loading, antidiuresis and hyponatremia $(125.4 \pm 1.4 \mathrm{mEq} / \mathrm{l})$ were significantly potentiated. V2R mRNA expression in kidney was significantly less in $\mathrm{Tg}$ rats than in control rats under basal conditions, and this suppression was restored by OPC31260 treatment to levels comparable with those of control rats. These results suggest that long-standing high plasma AVP causes V2R down-regulation, and it may play an important role in the adaptive mechanism(s) for maintaining water and electrolyte homeostasis in chronically AVP-overexpressing rats.

Journal of Endocrinology (2002) 173, 23-33

\section{Introduction}

The neurohypophyseal nonapeptide arginine vasopressin (AVP) is the most potent antidiuretic hormone that regulates water balance. It acts on the adenylate cyclasecoupled vasopressin V2 receptor (V2R) located in the renal collecting ducts (Brownstein 1983) and increases water reabsorption from primary urine through the aquaporin-2 (AQP2) water channel by stimulating its shuttling from intracellular vesicles into the apical plasma membrane and its synthesis (Knepper 1997, Marples et al. 1999).

AVP deficiency results in polyuria and polydipsia, symptomatic of diabetes inspidus. There is a genetic animal model, the Brattleboro rat, which fails to produce sufficient AVP due to a single base pair deletion in its AVP gene (Schmale \& Richter 1984). Since its discovery about 40 years ago (Valtin et al. 1962), the Brattleboro rat has proved to be very useful for studying the physiological consequence of AVP deficiency (Woods \& Johnston 1983, Stoehr et al. 1993, Walter et al. 1996). On the other hand, in some clinical circumstances, inappropriately high plasma AVP results in free water retention and hyponatremia (Bartter \& Schwartz 1967). After the first report from Murphy et al. (1987), several investigators have developed genetic models of AVP oversecretion using the transgenic technique. However, these animals did not demonstrate apparent water and electrolyte disorders (Habener et al. 1988, 1989, Miller et al. 1993, Waller et al. 1996).

Recently, we have generated a rat transgenic for the fusion gene consisting of the heavy metal-inducible 
promoter region of the mouse metallothionein I gene and human AVP gene (Nagasaki et al. 2002). We have revealed that in the rat (1) plasma AVP immunoreactivity was remarkably elevated and increased further by administering zinc sulfate, (2) AVP protein was processed correctly and revealed almost equivalent bioactivity with authentic AVP, and (3) the plasma $\left[\mathrm{Na}^{+}\right]$concentration was not different from control rats under basal conditions, while it declined compared with control rats when a liquid diet containing zinc was provided. Interestingly, the change in water and electrolyte balance was relatively mild in spite of a markedly elevated plasma AVP level. Considering other previous studies of AVP-overexpressing animals, our data suggest there might be some adaptive mechanism(s) maintaining the plasma $\left[\mathrm{Na}^{+}\right]$levels in the case of chronically high plasma AVP.

There could be several pathways for this change. Phosphorylation or internalization of the receptor plays a prominent role in the acute, short-term (seconds to minutes) adaptive response, and down-regulation of receptor mRNA or protein is concerned with the long-term (hours to days) response (Hadcock \& Malbon 1993). Since our AVP-overexpressing transgenic (Tg) rat is persistently exposed to high plasma AVP, we postulate that a long-term adaptive response, including down-regulation of $\mathrm{V} 2 \mathrm{R}$ in the kidney, contributes to the maintenance of water and electrolyte homeostasis.

To test this hypothesis, we performed the following five experiments: (1) basal values of water and electrolyte homeostasis were checked; (2) renal reactivity to exogenously administered AVP was tested; (3) the effect of water loading with further plasma AVP elevation on water and electrolyte balance was more extensively examined; (4) to reverse the down-regulation of V2R, orally effective non-peptidic V2R antagonist OPC31260 (Yamamura et al. 1992) was administered, and water loading was performed after withdrawal of the antagonist; and (5) to confirm the down-regulation, V2R mRNA expression was evaluated.

\section{Materials and Methods}

\section{Animals}

Male rats homozygous for the transgene and age-matched control (Sprague-Dawley), 9-13 weeks of age, were analyzed. Details of the preparation of the rat transgenic for the human AVP gene used in this study have been described (Nagasaki et al. 2002). Rats were maintained under controlled conditions $\left(23^{\circ} \mathrm{C}\right.$; lights on 0900 $2100 \mathrm{~h}$ ), and all procedures were performed in accordance with the institutional guidelines for animal care at Nagoya University School of Medicine, which conform with the NIH animal care guidelines.

\section{Materials}

Zinc liquid diet Commercial, nutritionally balanced liquid diet (Isocal plus, Mead-Johnson, Evansville, IN, USA) was diluted with an equal volume of $12.5 \mathrm{mM}$ zinc sulfate in order to stimulate the metal-responsive element of the metallothionein promoter in the transgene. The formula of this liquid diet supplies $0.75 \mathrm{kcal} / \mathrm{ml}$ consisting of $45 \%$ carbohydrate, $15 \%$ protein, and $40 \%$ fat, along with $7.3 \mathrm{mEq} / 1$ sodium. The zinc liquid diet was provided at a volume of $30 \%$ body weight (BW) daily.

Diet containing V2 antagonist Orally effective, nonpeptidic selective V2R antagonist OPC31260, which was a gift from Otsuka Pharmaceutical Co. Ltd (Tokyo, Japan), was mixed with standard rat chow at a concentration of $0 \cdot 05 \%$.

\section{Basal measurements}

For the measurement of urine excretion, age-matched $\mathrm{Tg}$ and control rats were housed in metabolic cages individually and provided with standard rat chow and water ad libitum. After 2 days of habituation to the metabolic cage, basal 24-h urine volume, urine osmolality and 24-h water intake were measured. All rats were decapitated for the measurement of plasma $\left[\mathrm{Na}^{+}\right]$and AVP. The left kidney was removed for immunoblotting using antiAQP2 antibody. There were five $\mathrm{Tg}$ and five control rats.

\section{Renal reactivity to exogenously administered AVP}

Renal reactivity to AVP was tested essentially as described in a previous report (Musabayane et al. 1985). In brief, rats were anesthetized with $2 \cdot 1 \mathrm{M}$ ethanol in distilled water $(5 \mathrm{ml} / 100 \mathrm{~g} \mathrm{BW})$ administered by stomach tube and then placed on a continuous jugular infusion of $0.075 \mathrm{M} \mathrm{NaCl}$ and $0.44 \mathrm{M}$ ethanol at $150 \mu \mathrm{l} / \mathrm{min}$. The urinary bladder was cannulated via an incision in the abdominal wall and urine was collected into a preweighed tube every $3 \mathrm{~min}$. After an equilibration period, $200 \mathrm{pg}$ AVP (Peptide Institute, Osaka, Japan) dissolved in $200 \mu \mathrm{l} 0.15 \mathrm{M}$ $\mathrm{NaCl}$ was injected i.v. Urine volume was determined gravimetrically. There were three $\mathrm{Tg}$ and four control rats.

\section{Effect of water loading}

After 2 days of habituation to the metabolic cage, basal 24-h urine excretion and 24-h water intake were measured, and then the zinc liquid diet was provided once daily at a volume of $30 \% \mathrm{BW}$ without the chow to induce excess water intake. During the experiment, tap water was removed. Daily total urine volume, osmolality and $\left[\mathrm{Na}^{+}\right]$ were measured. Rats were killed $12 \mathrm{~h}$ after the last zinc liquid diet had been provided at each of five different time-points ( 1 day prior to water loading (day 0$)$, and 1,2 , 4 , and 7 days after the start of water loading (days 1, 2, 4, 

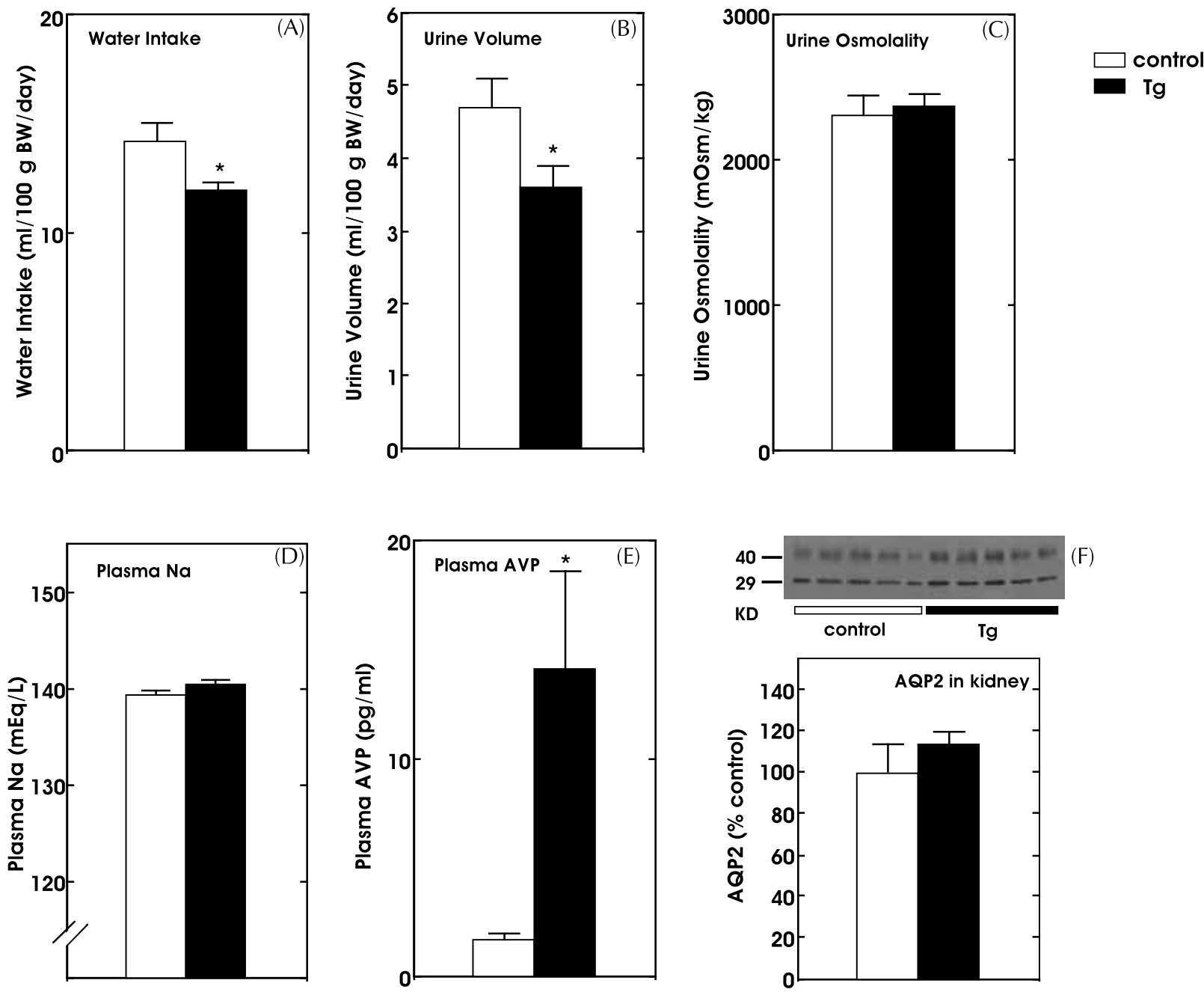

Figure 1 Basal measurements. For measurement of 24-h urine excretion, age-matched Tg and control rats were individually housed in metabolic cages. After 2 days of habituation to the metabolic cages, (A) daily water intake, (B) urine volume, and (C) urine osmolality were measured. All rats were decapitated for measuring plasma (D) $\left[\mathrm{Na}^{+}\right]$and (E) plasma AVP. (F) Kidney AQP2 protein. Upper panel, immunoblots (each lane was loaded with a sample from a different rat). Sharp band at $29 \mathrm{kDa}$ (KD): AQP2 protein; broad band at 40 kDa: glycosylated form of AQP2. Lower panel, densitometry data of blot. There were five Tg and five control rats. ${ }^{*} P<0 \cdot 05$ vs control rat.

and 7 respectively) for measuring plasma $\left[\mathrm{Na}^{+}\right]$and AVP. There were six Tg and six control rats except for day 0 and day 1 (12 Tg and 12 control rats each). Plasma total protein (TP) was measured on day 0 and day 1 ( $n=6$ each).

\section{Effect of water loading after V2 antagonist pretreatment}

As shown in Fig. 4A, to reverse desensitization of AVP action caused by long-standing high plasma AVP, diet containing V2 antagonist was provided ad libitum for 4 days (from day -4 to day -1 ) and withdrawn. During the V2 antagonist pretreatment, rats were allowed free access to water. Half of the V2 antagonist-pretreated group were decapitated to measure plasma $\left[\mathrm{Na}^{+}\right]$and AVP. Twelve hours after removing the diet containing V2R antagonist, the remaining rats were provided with the zinc liquid diet, and daily total urine excretion and urine osmolality were measured using the metabolic cage (day 1). Some other $\mathrm{Tg}$ and control rats were provided with the zinc liquid diet without V2 antagonist pretreatment. Twenty-four hours after the zinc liquid diet had been provided, all rats were decapitated to measure plasma $\left[\mathrm{Na}^{+}\right]$and AVP. There were six $\mathrm{Tg}$ and six control rats in each group.

\section{Immunoblotting}

The inner medulla was dissected from the left kidney which was sliced along the corticomedullary axis and 
homogenized in $1 \mathrm{ml}$ chilled isolation solution containing $250 \mathrm{mM}$ sucrose, $10 \mathrm{mM}$ triethanolamin, and $1 \mu \mathrm{g} / \mathrm{ml}$ leupeptin (Sigma, St Louis, MO, USA) and $0.1 \mathrm{mg} / \mathrm{ml}$ phenylmethylsulfonyl fluoride adjusted to $\mathrm{pH} 7 \cdot 6$. Protein concentration was measured with a Micro BCA Protein Assay Reagent Kit (Pierce, Rockford, IL, USA). All samples were diluted to $2 \mu \mathrm{g}$ protein/ $\mu$ l with sample buffer containing $125 \mathrm{mM}$ Tris, 2\% SDS, and 10\% glycerol adjusted to $\mathrm{pH} 6 \cdot 8$, then solubilized at $60{ }^{\circ} \mathrm{C}$ for $15 \mathrm{~min}$. SDS-PAGE was carried out, and protein was electrophoretically transferred from gel to a nitrocellulose membrane (Hybond ECL; Amersham Pharmacia Biotech, Amersham, Bucks, UK). The membrane was blocked for an hour in 5\% skimmed milk and was then probed for $48 \mathrm{~h}$ with affinity-purified rabbit polyclonal antibodies directed against AQP2 (kindly provided by Dr M A Knepper) diluted at 1:500 with a solution containing $137 \mathrm{mM} \mathrm{NaCl}$, $4 \cdot 0 \mathrm{mM} \mathrm{KCl}, 25 \mathrm{mM}$ Tris adjusted to $\mathrm{pH} 7 \cdot 4,50 \mu \mathrm{l} / \mathrm{dl}$ Tween 20 , and $0 \cdot 1 \mathrm{~g} / \mathrm{dl}$ bovine serum albumin. The second antibody was goat anti-rabbit IgG conjugated to horseradish peroxidase (New England Bio Labs Inc., Beverly, CA, USA) diluted at 1:1000. Antibody-antigen reaction was visualized by chemiluminescence reaction using ECL Western blotting detection reagents (Amersham Pharmacia Biotech). Relative quantitation of the band density from the immunoblots was performed by densitometry using NIH image-analysis software.

\section{Preparation of RNA and Northern blotting}

Age-matched Tg and control rats were fed a diet containing V2 antagonist for 4 days or fed continuously with standard rat chow. They were killed by decapitation, and the left kidney was rapidly removed, wrapped in aluminium foil, and frozen by burying it in dry ice. The kidneys, which had been frozen at $-80{ }^{\circ} \mathrm{C}$, were warmed very briefly to near $0{ }^{\circ} \mathrm{C}$, and sliced along the corticomedullary axis to dissect the inner medulla. Total RNA was extracted from the kidney inner medulla using TRIzol Reagent (Gibco-BRL, Life Technologies Inc., Rockville, MD, USA) according to the manufacturer's recommendation. The amount of RNA was determined by the spectrophotometric method. Each $10 \mu \mathrm{g}$ total RNA was size-fractionated and transferred to a nylon membrane (Gene Screen Plus Hybridization Membrane; Biotechnology Systems, NEN Research Products, Boston, MA, USA) for Northern blot hybridization using a ${ }^{32} \mathrm{P}-$ labeled $602 \mathrm{bp}$ cDNA probe designed specifically for rat $\mathrm{V} 2 \mathrm{R}$ cDNA. The probe was generated by PCR (Terashima et al. 1999). To ensure even loading, the membrane was washed and then rehybrized with rat glyceraldehyde-3-phosphate dehydrogenase (GAPDH) cDNA probe (Fort et al. 1985). The integrated radioactivity of the mRNA band for V2R and GAPDH was quantified with a Bio-Image Analyzer (BAS2000; Fuji Photo Film Co. Ltd, Tokyo, Japan). The changes in V2R

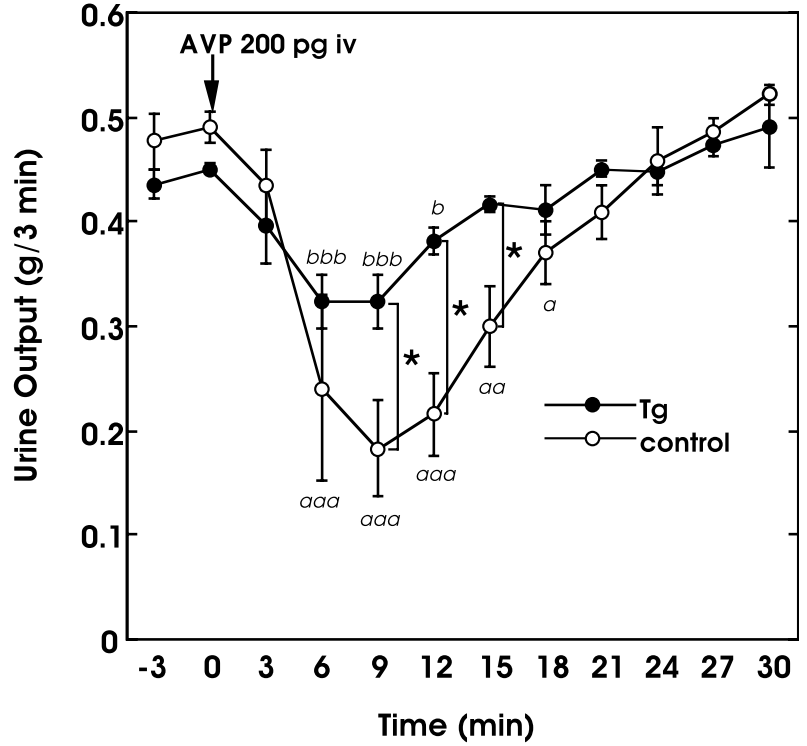

Figure 2 Renal reactivity to exogenously administered AVP. Rats were anesthetized with $2 \cdot 1 \mathrm{M}$ ethanol in distilled water $(5 \mathrm{ml} / 100 \mathrm{~g}$ BW) administered by stomach tube and then placed on a continuous jugular infusion of $0.075 \mathrm{M} \mathrm{NaCl}$ and $0.44 \mathrm{M}$ ethanol at $150 \mu \mathrm{l} / \mathrm{min}$. Urine was collected every $3 \mathrm{~min}$. After an equilibration period, $200 \mathrm{pg}$ AVP was injected i.v. There were three Tg and four control rats. ${ }^{*} P<0.05$ vs control rat. ${ }^{a} P<0.05$ vs urine output of control rats at 0 min. ${ }^{\text {aa }} P<0 \cdot 01$ vs urine output of control rats at $0 \mathrm{~min}$. ${ }^{\text {aaa }} P<0.001$ vs urine output of control rats at 0 min. ${ }^{b} P<0.05$ vs urine output of $\mathrm{Tg}$ rats at $0 \mathrm{~min} .{ }^{b b b} P<0 \cdot 001$ vs urine output of $\mathrm{Tg}$ rats at $0 \mathrm{~min}$.

mRNA expression are presented as the percentage changes from non-treated control rats after correction for GAPDH mRNA expression. There were four $\mathrm{Tg}$ and four control rats in each group.

\section{Blood pressure measurement}

Systolic blood pressure (SBP) was measured by tail-cuff sphygmomanometer (soft ran BP-98A; Omron, Tokyo, Japan) in conscious $\mathrm{Tg}$ and control rats, which were fed with standard chow, zinc liquid or diet containing V2 antagonist. The SBP value was the mean of more than three successive measurements. There were six Tg and six control rats in each group.

\section{Plasma AVP and sodium measurements}

Blood samples were collected in chilled tubes containing EDTA (potassium salt) for AVP assay. After immediate separation, plasma AVP was extracted through a Sep-Pak C18 Cartridge (Waters Associates Inc., Milford, MA, USA) and measured using a highly sensitive radioimmunoassay (RIA) kit (AVP-RIA kit, kindly provided by Mitsubishi Chemical Co. Ltd, Tokyo, Japan) (Oiso 

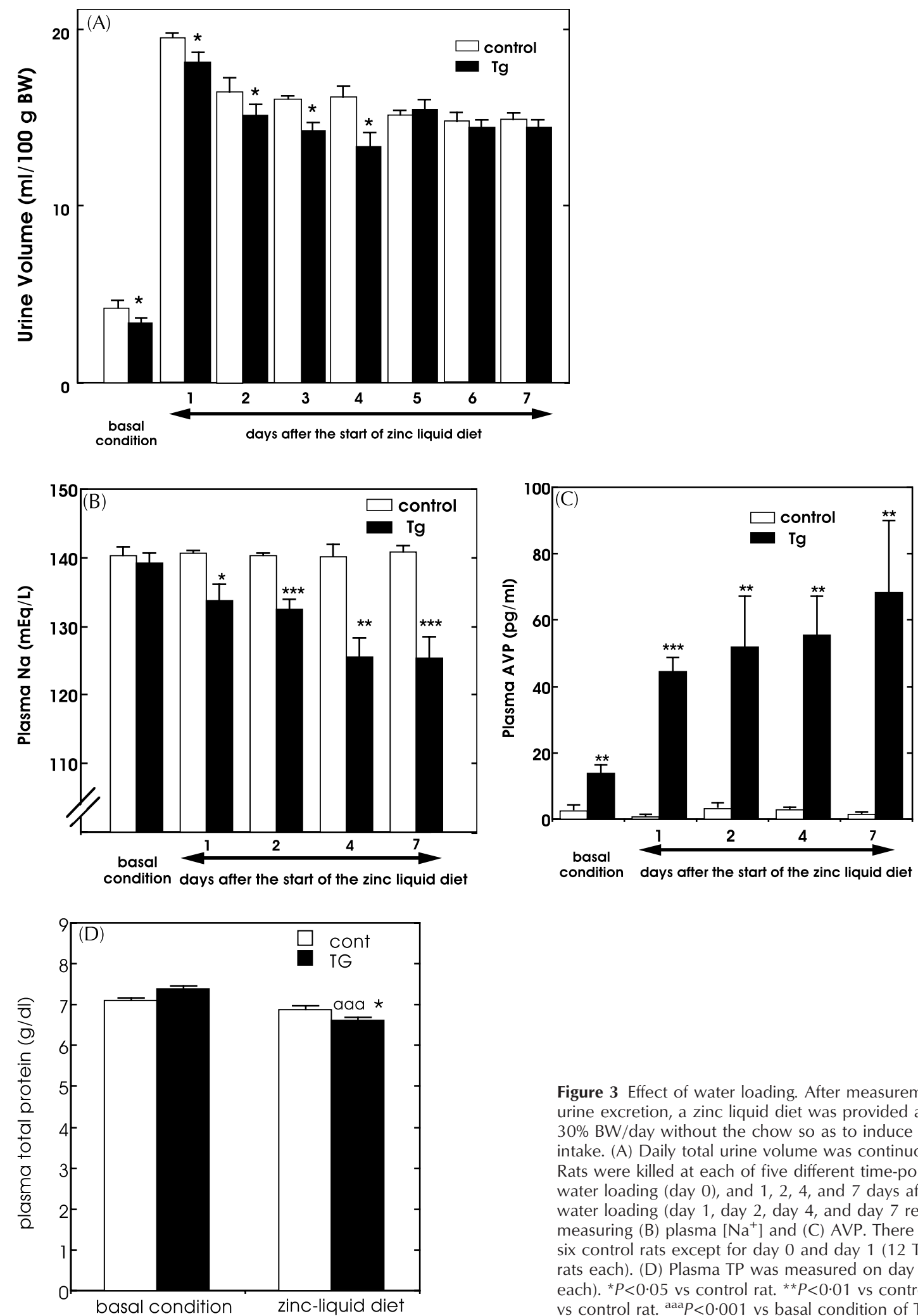

Figure 3 Effect of water loading. After measurement of basal daily urine excretion, a zinc liquid diet was provided at a volume of $30 \% \mathrm{BW} /$ day without the chow so as to induce excess water intake. (A) Daily total urine volume was continuously measured. Rats were killed at each of five different time-points ( 1 day prior to water loading (day 0 ), and $1,2,4$, and 7 days after the start of water loading (day 1 , day 2 , day 4 , and day 7 respectively)) for measuring (B) plasma $\left[\mathrm{Na}^{+}\right]$and (C) AVP. There were six Tg and six control rats except for day 0 and day 1 (12 Tg and 12 control rats each). (D) Plasma TP was measured on day 0 and day $1(n=6$ each). ${ }^{\star} P<0 \cdot 05$ vs control rat. ${ }^{* *} P<0 \cdot 01$ vs control rat. ${ }^{* * * P} P<0 \cdot 001$ vs control rat. ${ }^{\text {aaa }} P<0.001$ vs basal condition of Tg rats. 

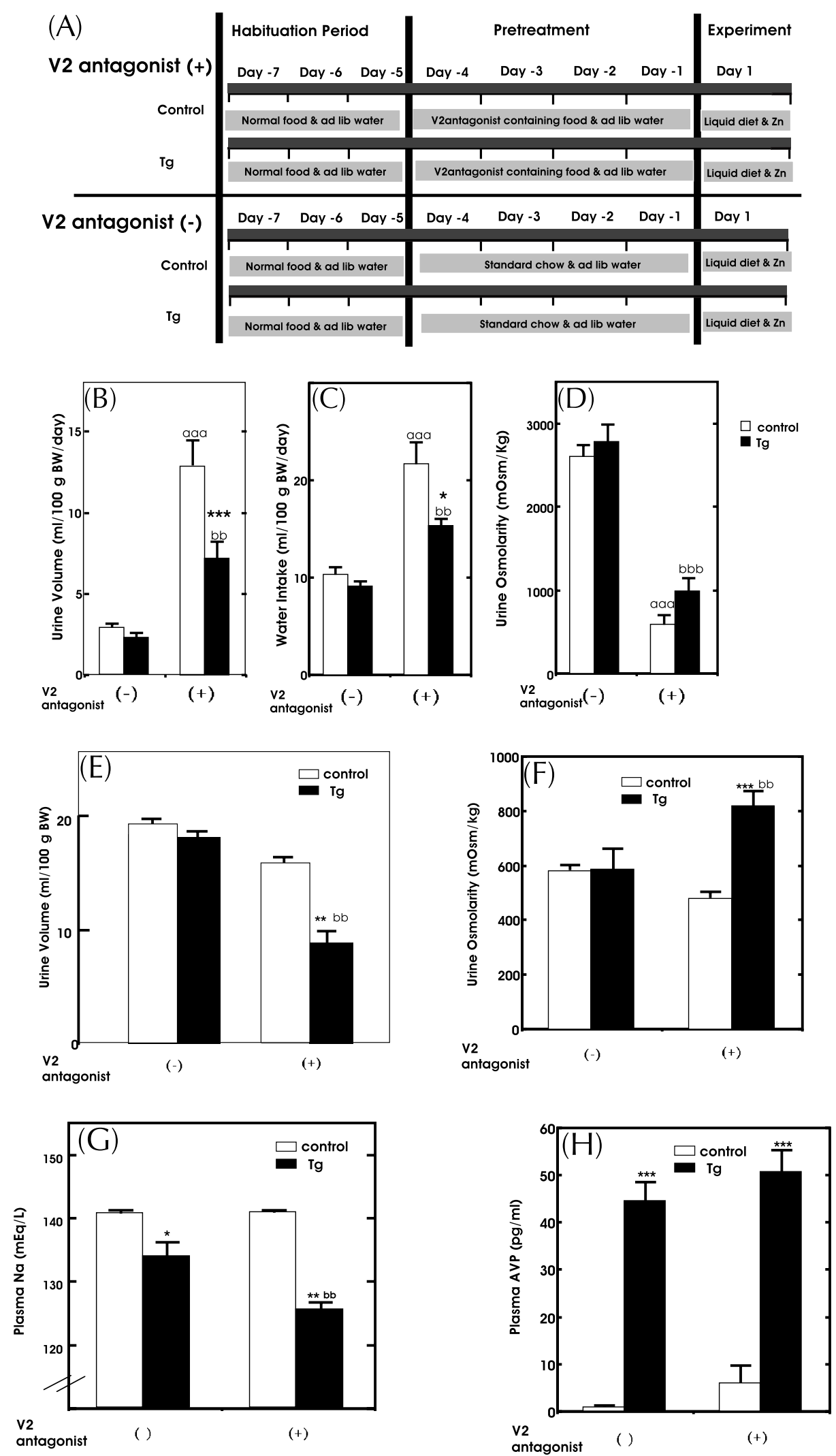
et al. 1988). Plasma $\left[\mathrm{Na}^{+}\right]$was measured using an autoanalyzer (Hitachi Ltd, Tokyo, Japan).

\section{Statistics}

Results are expressed as the means \pm S.E.M. Statistical analyses were performed using one-way ANOVA followed by Fisher's PLSD test for multiple comparisons. Differences were considered statistically significant at $P<0 \cdot 05$.

\section{Results}

\section{Basal measurements}

Under basal conditions, daily water intake (Fig. 1A) and urine volume (Fig. 1B) of Tg rats had slightly decreased compared with control rats; however, urine osmolality (Fig. 1C) failed to demonstrate significant difference. Plasma $\left[\mathrm{Na}^{+}\right]$showed no significant difference between $\mathrm{Tg}$ and control rats (Fig. 1D) under basal conditions despite plasma AVP being extremely elevated in $\mathrm{Tg}$ rats (Fig. 1E). AQP2 protein in kidney inner medulla did not show a significant difference between $\mathrm{Tg}$ and control rats (Fig. 1F).

\section{Renal reactivity to exogenously administered AVP}

In control rats, AVP rapidly revealed an antidiuretic effect, and urine excretion decreased to $40 \%$ of the basal value 9 min after the injection. In Tg rats, its antidiuretic effect was attenuated $(70 \%$ of the basal value at $9 \mathrm{~min}$ after the injection) compared with control rats (Fig. 2).

\section{Effect of water loading}

Both $\mathrm{Tg}$ and control rats drank all the zinc liquid diet within the first few hours of administration. As a consequence of water loading, urine volume increased remarkably in both control and $\mathrm{Tg}$ rats (Fig. 3A). In Tg rats, although AVP secretion was markedly stimulated by zinc sulfate (Fig. 3C), urine volume was decreased only slightly compared with control rats (Fig. 3A). This suppression was observed until day 4 (Fig. 3A). Urine osmolality decreased remarkably after initiation of water loading in both control rats (from $2304 \pm 141$ (basal) to $580 \pm 19 \mathrm{mOsm} / \mathrm{kg}$ (day 1), $P<0 \cdot 001$ ) and $\mathrm{Tg}$ rats (from $2368 \pm 85$ (basal) to
Table 1 Effect of $\mathrm{V} 2$ antagonist on plasma $\left[\mathrm{Na}^{+}\right]$and AVP. Values are means \pm S.E.M.; $n=6$

\begin{tabular}{|c|c|c|}
\hline & Standard chow & $\begin{array}{l}\text { Diet containing } \\
\text { V2 antagonist }\end{array}$ \\
\hline \multicolumn{3}{|c|}{ Plasma $\left[\mathrm{Na}^{+}\right](\mathrm{mEq} / \mathrm{l})$} \\
\hline Control & $139 \cdot 3 \pm 0 \cdot 6$ & $141 \cdot 0 \pm 1 \cdot 2$ \\
\hline $\operatorname{Tg}$ & $141 \cdot 2 \pm 0 \cdot 9$ & $141 \cdot 1 \pm 0 \cdot 9$ \\
\hline \multicolumn{3}{|c|}{ Plasma AVP (pg/ml) } \\
\hline Control & $2 \cdot 3 \pm 0 \cdot 2$ & $13 \cdot 8 \pm 0 \cdot 1^{\# \# \#}$ \\
\hline $\operatorname{Tg}$ & $15 \cdot 6 \pm 2 \cdot 9^{\star \star *}$ & $17 \cdot 3 \pm 1 \cdot 8$ \\
\hline
\end{tabular}

Rats were fed, for 4 days, a diet containing V2 antagonist or 0.05\% OPC31260, or a normal diet, then decapitated to measure plasma $\left[\mathrm{Na}^{+}\right]$ and AVP.

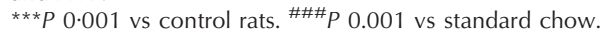

$585 \pm 72 \mathrm{mOsm} / \mathrm{kg}$ (day 1), $P<0 \cdot 001$ ). Neither urine osmolality nor daily $\left[\mathrm{Na}^{+}\right]$excretion (urinary $\left[\mathrm{Na}^{+}\right] \times$urine volume) showed a significant difference between $\mathrm{Tg}$ and control rats (data not shown). However, cumulative $\left[\mathrm{Na}^{+}\right]$excretion from the start of water loading became slightly higher in $\mathrm{Tg}$ than in control rats after day 3 (day 3, control rats $18 \cdot 9 \pm 0 \cdot 3 \mathrm{mEq} / \mathrm{kg} \mathrm{BW} ; \mathrm{Tg}$ $20.5 \pm 0.4 \mathrm{mEq} / \mathrm{kg} \mathrm{BW}, P<0.01$; day 7 , control rats $36 \cdot 7 \pm 0.6 \mathrm{mEq} / \mathrm{kg} \mathrm{BW} ; \mathrm{Tg} 39 \cdot 8 \pm 1 \cdot 2 \mathrm{mEq} / \mathrm{kg} \mathrm{BW}$, $P<0 \cdot 05)$. In response to water loading, plasma $\left[\mathrm{Na}^{+}\right]$ decreased gradually and plateaued at $125 \mathrm{mEq} / 14$ days after initiation of water loading in Tg rats, whereas it did not demonstrate any significant change in control rats (Fig. 3B). Plasma TP did not show a significant difference between $\mathrm{Tg}$ and control rats under basal conditions. After providing zinc liquid diet, TP significantly decreased compared with the basal value, whereas plasma TP of control rats did not change (Fig. 3D).

\section{Effect of water loading after V2 antagonist pretreatment}

V2 antagonist caused a significant increase in urine volume and a decrease in urine osmolality in both $\mathrm{Tg}$ and control rats (Fig. 4B and D respectively). Their effects were attenuated in Tg compared with control rats. After 4 days of V2 antagonist pretreatment, plasma AVP increased markedly in control rats, but was unaffected in $\mathrm{Tg}$ rats (Table 1). In addition, V2R antagonist had no effect on plasma $\left[\mathrm{Na}^{+}\right]$, which was not significantly different between $\mathrm{Tg}$ and control rats either before or after pretreatment (Table 1). BW was not altered by the diet containing

Figure 4 Effect of water loading after V2 antagonist pretreatment. To reverse desensitization of AVP action caused by long-standing high plasma AVP, a diet containing V2 antagonist was provided ad libitum for 4 days (from day -4 to day -1 ), and then animals were switched to the zinc liquid diet (day 1 ) (A). Daily total urine volume and urine osmolality were measured on day -4 (B and D respectively) and day 1 ( $E$ and $F$ respectively). Water intake was measured on day -4 (C). Some other Tg and control rats were provided with the zinc liquid diet without V2 antagonist pretreatment. Twenty-four hours after the zinc liquid diet was provided, the rats were decapitated for measuring plasma $\left[\mathrm{Na}^{+}\right](\mathrm{G})$ and $\mathrm{AVP}(\mathrm{H})$. There were six $\mathrm{Tg}$ and six control rats in $\mathrm{V} 2$ antagonist-pretreated group. ${ }^{\star} P<0 \cdot 05$ vs control rats. ${ }^{* *} P<0 \cdot 01$ vs control rats. ${ }^{* *} P<0 \cdot 001$ vs control rats. ${ }^{\text {aaa }} P<0 \cdot 001$ vs $\mathrm{V} 2$ antagonist $(-)$ control rats. bb $P<0 \cdot 01$ vs $\mathrm{V} 2$ antagonist $(-)$ Tg rats. ${ }^{\text {bbb }} P<0.001$ vs $\mathrm{V} 2$ antagonist $(-)$ Tg rats. 

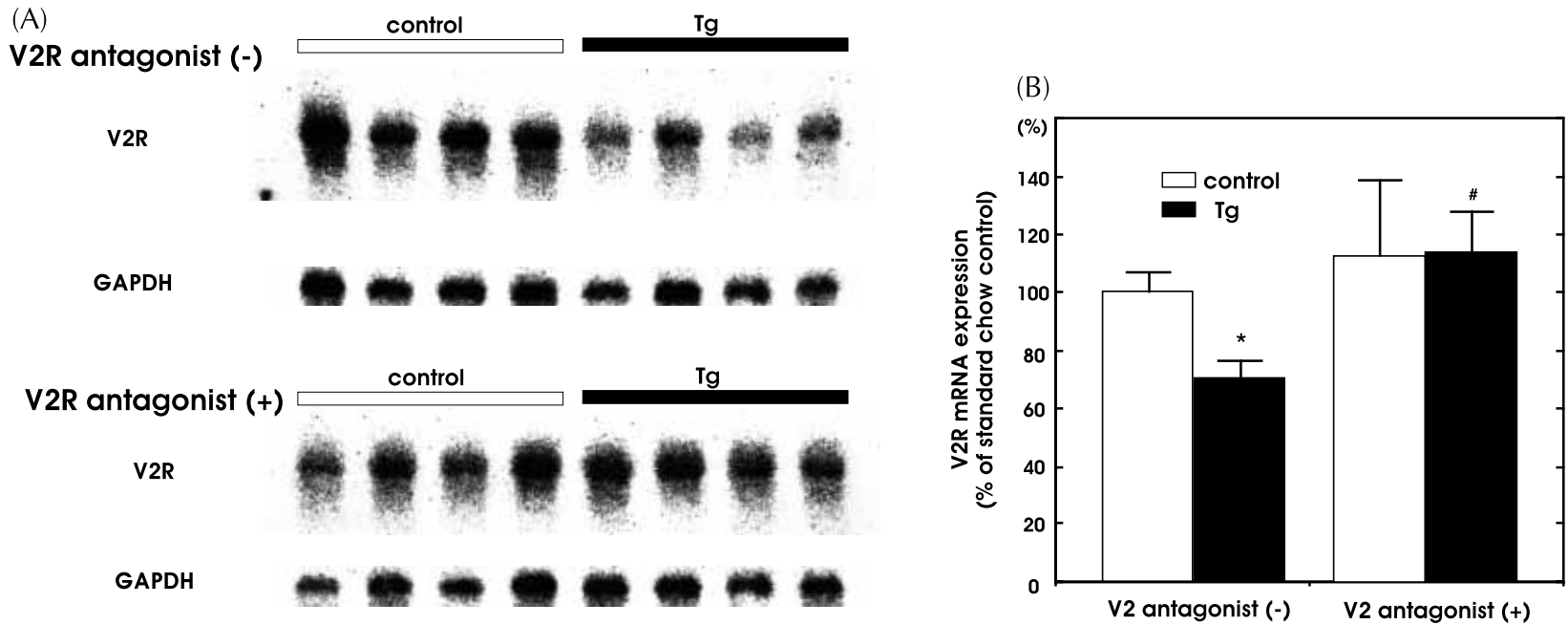

Figure $5 \mathrm{~V} 2 \mathrm{R}$ mRNA expression in kidney inner medulla. Age-matched Tg and control rats fed a diet containing V2 antagonist for 4 days or standard rat chow continuously were killed by decapitation. Northern analysis of V2R from kidney inner medulla was carried out as described in Materials and Methods. (A) Northern blots (each lane was loaded with sample from a different rat). (B) Densitometry data of blot. There were four Tg and four control rats in each group. ${ }^{*} P<0 \cdot 05$ vs control rat. ${ }^{\#} P<0 \cdot 05$ vs standard chow.

V2 antagonist. In Tg rats, withdrawal of V2 antagonist pretreatment significantly potentiated suppression of urine excretion in response to water loading (Fig. 4E) and significantly elevated urine osmolality (Fig. 4F) compared with non-pretreated $\mathrm{Tg}$ rats. However, in control rats, there was no significant effect on urine volume (Fig. 4E) or urine osmolality (Fig. 4F) after water loading. It was also found that more potent hyponatremia was induced by water loading in Tg rats with V2 antagonist pretreatment, which had been stopped before starting the zinc liquid diet (Fig. 4G) despite there being no difference in plasma AVP levels between the V2 antagonist-pretreated group and non-pretreated group (Fig. $4 \mathrm{H}$ ). BW increased by $6.0 \%$ $24 \mathrm{~h}$ after water loading in V2 antagonist-pretreated $\mathrm{Tg}$ rats, but did not significantly increase in non-pretreated $\mathrm{Tg}$ rats or in either pretreated or non-pretreated control rats (data not shown).

\section{$V 2 R m R N A$ expression}

In $\mathrm{Tg}$ rats, $\mathrm{V} 2 \mathrm{R}$ mRNA expression in kidney inner medulla was significantly less than in control rats under the basal conditions, and this suppression was restored by V2 antagonist treatment to levels comparable with those of controls rats. In control rats, V2 antagonist treatment had no significant effect on V2R mRNA expression (Fig. 5).

\section{Blood pressure measurement}

There was no significant difference between $\mathrm{Tg}$ and control rats in SBP under basal condition (control rats $117 \pm 3 \mathrm{mmHg}$; Tg $115 \pm 3 \mathrm{mmHg}$ ). Neither zinc liquid diet nor diet containing V2 antagonist exerted a significant effect on SBP (zinc liquid diet: control rats $120 \pm 4$ $\mathrm{mmHg}, \mathrm{Tg} 116 \pm 3 \mathrm{mmHg}$; diet containing V2 antagonist: control rats $114 \pm 4 \mathrm{mmHg}, \mathrm{Tg} 116 \pm 2 \mathrm{mmHg}$ ).

\section{Discussion}

In this study, basal physiological measurements with regard to water and electrolyte homeostasis, as well as plasma AVP and AQP2 protein levels in the kidney inner medulla were performed in $\mathrm{Tg}$ rats. While plasma AVP was markedly elevated, urine volume and water intake did not show dramatic changes, with an almost equivalent AQP2 protein level in the kidney. Renal reactivity to exogenously administered AVP using overhydrated, alcohol-anesthetized Tg rats clearly revealed desensitization of its antidiuretic action. Providing the zinc liquid diet, which induces potent water loading and further plasma AVP elevation by stimulating metal responsive elements in the transgene, demonstrated disruption of renal water excretion and developed hyponatremia in response to it in $\mathrm{Tg}$ rats. However, the alteration in water and electrolyte balance was relatively mild in spite of the extremely high plasma AVP levels. We also showed that V2R mRNA was down-regulated in Tg rats, and that OPC31260 pretreatment reversed the down-regulation and potentiated the antidiuretic action of AVP.

There have been several AVP-overexpressing transgenic animals before ours (Murphy et al. 1987, Habener et al. 1989, Grant et al. 1993). However, to our knowledge, no group has demonstrated hyponatremia or water retention caused by AVP-induced antidiuresis. Habener et al. (1989) reported that the renal plasma membrane 
fraction from their AVP-overexpressing transgenic mice showed diminished activation of adenylate cyclase following in vitro exposure to AVP, and they concluded that the animals had a nephrogenic diabetes inspidus-like state due to AVP receptor desensitization. We have generated AVP-overexpressing transgenic animals using the rat as a host animal. Rats enable more precise physiological analyses, such as urine volume or water intake, than mice and provide blood samples large enough to measure plasma AVP, which needs extraction before being applied to RIA. Our Tg rats showed slightly decreased urine volume with a normal plasma $\left[\mathrm{Na}^{+}\right]$level and AQP2 protein amount in the kidney under basal conditions. AVP regulates the water permeability of the renal collecting duct, not only by increasing expression of AQP2 (DiGiovanni et al. 1994, Marples et al. 1999) but also by transport of vesicles containing AQP2 to the apical plasma membrane (Knepper 1997). With regard to the discrepancy in the data for urine volume and AQP2 protein in this study, it is possible that the distribution of AQP2 protein in the collecting duct cell might be altered in Tg rats. Next, we investigated the effect of water loading with further plasma AVP elevation with the zinc liquid diet. As expected, plasma AVP concentration potently increased by stimulating the transgene. Plasma $\left[\mathrm{Na}^{+}\right]$decreased gradually and plateaued at day 4 . Water loading-induced diuresis was slightly suppressed until day 4, and plasma TP decreased in $\mathrm{Tg}$ rats compared with the basal value, suggesting water retention. Although daily urinary $\left[\mathrm{Na}^{+}\right]$excretion never showed a significant difference, cumulative urinary $\left[\mathrm{Na}^{+}\right]$ excretion slightly increased in $\mathrm{Tg}$ rats after day 3 . Considering that hyponatremia was already established at day 3 , the natreuresis may contribute to the maintenance of hyponatremia rather than its induction. This is consistent with a previous report of Verbalis (1994), which elucidated the mechanism of prolonged hyponatremia in his rat model of the syndrome of inappropriate antidiuretic hormone secretion. Overall, we have confirmed the physiological action of AVP in Tg rats. Considering the remarkably high plasma AVP in Tg rats, disruption of water and electrolyte homeostasis was very mild.

Verbalis \& Drutarosky (1988) reported that continuous AVP infusion followed by excessive administration of water results in water retention and hyponatremia. However, daily water excretion began to increase in spite of sustained AVP infusion several days after initiation of water loading, namely the 'vasopressin escape phenomenon' (Verbalis \& Drutarosky 1988, Murase et al. 1999, Tian et al. 2000). In our transgenic animal model, the escape from AVP-induced antidiuresis was already observed on the first day of water loading. Furthermore, the decrease in plasma $\left[\mathrm{Na}^{+}\right]$was much less even with more extensive water loading in rats with a plasma AVP level comparable with their study (Verbalis 1984). This evidence indicates that a potent adaptive mechanism for maintaining water and electrolyte homeostasis might be established in the case of chronic AVP oversecretion from the earliest stage of life in Tg rats.

The antidiuretic effect of vasopressin is mediated by $\mathrm{V} 2 \mathrm{R}$, which belongs to a large family of $\mathrm{G}$ proteincoupled receptors (GPCRs) with a typical seven transmembrane helix structure (Bichet 1994), located in the kidney collecting ducts (Ostrowski et al. 1992). Continuous or repeated exposure to an agonist promotes desensitization of GPCRs, and the attenuation of the hormonal response in spite of the presence of hormone, through short- and long-term regulation. Short-term regulation of transmembrane signaling appears to be largely independent of changes in gene expression such as phosphorylation or internalization of the receptor. Long-term regulation, in contrast, often reflects changes in the steady levels of mRNA or protein levels and/or changes in the turnover of receptor which causes down-regulation of receptor expression (Hadcock \& Malbon 1993, Morris 1993).

Since we postulated that V2R down-regulation induced by long-standing high plasma AVP is responsible for the adaptive mechanism, we tried to reverse the down-regulation. $\beta$-Adrenoceptor, widely adopted as a prototype for the study of the regulation of GPCRs (Dohlman et al. 1991), increases in number when $\beta$-adrenoceptor blocking drugs are administered (Frishman 1987, van den Meiracker et al. 1989). Therefore, we used the non-peptidic antagonist OPC31260, which has been reported not to induce visible receptor internalization (Pfeiffer et al. 1998), so as to reverse the down-regulation for several days, after which water loading was performed. Interestingly, the diuretic effect of OPC31260 by blocking V2R was attenuated in Tg rats, in which V2R had already been partly blocked by the down-regulation. As expected, withdrawal of V2 antagonist pretreatment followed by water loading resulted in the potentiation of AVP-induced antidiuresis in Tg rats. Since blood pressure was not altered by the zinc liquid diet or V2 antagonist in both $\mathrm{Tg}$ and control rats, this effect is unlikely to be due to cardiovascular modification. Additionally, Northern blotting analysis for V2R in this study, which demonstrated suppressed V2R mRNA expression under basal conditions and its recovery after V2 antagonist treatment, was consistent with our hypothesis.

However, compared with a previous report from our laboratory (Terashima et al. 1998) regarding V2R mRNA down-regulation using dehydrated normal rats, the suppression of V2R mRNA in the basal state of $\mathrm{Tg}$ rats in the present study ( $75 \%$ of control rats) was less than the suppression in dehydrated Sprague-Dawley rats $(65 \%$ of non-dehydrated), despite a higher plasma AVP level and a much longer duration in $\mathrm{Tg}$ rats than in the dehydrated normal rats in the previous study. Although the exact mechanism of agonist-induced desensitization is not yet fully understood, when considering the fact that AQP2 protein did not significantly increase under basal conditions in $\mathrm{Tg}$ rats, there may be a contribution from some 
other mechanism(s), such as a change in the $\mathrm{G}$ protein or adenyle-cyclase regulation in the downstream signal transduction system of $\mathrm{V} 2 \mathrm{R}$ prior to AQP2 expression (Laycock \& Hanoune 1998). Our animal model will be useful to clarify the in vivo adaptive mechanism in the hormone excess state.

In conclusion, Tg rats showed attenuated AVP-induced antidiuresis and minimum disruption in water and electrolyte homeostasis. The down-regulation of $\mathrm{V} 2 \mathrm{R}$ might, at least in part, be responsible for maintaining the homeostasis.

\section{Acknowledgements}

We are grateful to Dr Knepper, Laboratory of Kidney and Electrolyte Metabolism, NHLBI, NIH, for kindly providing the antibody against AQP2, to Otsuka Pharmaceuticals Co. Ltd for donating OPC31260 and giving helpful technical advice, and to the Institute for Laboratory Animal Research of Nagoya University School of Medicine for maintenance of the animals. This work was supported in part by the Research for the Future Program, the Japan Society for the Promotion of Science (JSPS-RFTF97I00201) and by a Grant-in-Aid for Scientific Research (B) from the Ministry of Education, Science, Sports and Culture, Japan (08457263).

\section{References}

Bartter FC \& Schwartz WB 1967 The syndrome of inappropriate secretion of antidiuretic hormone. American Journal of Medicine $\mathbf{4 2}$ 790-806.

Bichet DG 1994 Molecular and cellular biology of vasopressin and oxytocin receptors and action in the kidney. Current Opinion in Nephrology and Hypertension 3 46-53.

Brownstein MJ 1983 Biosynthesis of vasopressin and oxytocin. Annual Review of Physiology 45 129-135.

DiGiovanni SR, Nielsen S, Christensen EI \& Knepper MA 1994 Regulation of collecting duct water channel expression by vasopressin in Brattleboro rat. PNAS 91 8984-8988.

Dohlman HG, Thorner J, Caron MG \& Lefkowitz RJ 1991 Model systems for the study of seven-transmembrane-segment receptors. Annual Review of Biochemistry 60 653-688.

Fort P, Marty L, Piechaczyk M, el Sabrouty S, Dani C, Jeanteur P \& Blanchard JM 1985 Various rat adult tissues express only one major mRNA species from the glyceraldehyde-3-phosphatedehydrogenase multigenic family. Nucleic Acids Research $\mathbf{1 3}$ 1431-1442.

Frishman WH 1987 Beta-adrenergic blocker withdrawal. American Journal of Cardiology 59 26F-32F.

Grant FD, Reventos J, Kawabata S, Miller M, Gordon JW \& Majzoub JA 1993 Transgenic mouse models of vasopressin expression. Hypertension 22 640-645.

Habener JF, Cwikel B, Hermann H, Hammer RE, Palmiter RD \& Brinster RL 1988 Expression of a metallothionein-vasopressin fusion gene in transgenic mice produces hypervasopressinemia and manifestations of nephrogenic diabetes insipidus. Transactions of the Association of American Physicians 101 155-162.

Habener JF, Cwikel BJ, Hermann H, Hammer RE, Palmiter RD \& Brinster RL 1989 Metallothionein-vasopressin fusion gene expression in transgenic mice. Nephrogenic diabetes insipidus and brain transcripts localized to magnocellular neurons. Journal of Biological Chemistry 264 18844-18852.

Hadcock JR \& Malbon CC 1993 Agonist regulation of gene expression of adrenergic receptors and G proteins. Journal of Neurochemistry $601-9$.

Knepper MA 1997 Molecular physiology of urinary concentrating mechanism: regulation of aquaporin water channels by vasopressin. American Journal of Physiology 272 F3-F12.

Laycock JF \& Hanoune J 1998 From vasopressin receptor to water channel: intracellular traffic, constraint and by-pass. Journal of Endocrinology 159 361-372.

Marples D, Frokiaer J \& Nielsen S 1999 Long-term regulation of aquaporins in the kidney. American Journal of Physiology 276 F331-F339.

van den Meiracker AH, Man in't Veld AJ, Boomsma F, Fischberg DJ, Molinoff PB \& Schalekamp MA 1989 Hemodynamic and beta-adrenergic receptor adaptations during long-term beta-adrenoceptor blockade. Studies with acebutolol, atenolol, pindolol, and propranolol in hypertensive patients. Circulation $\mathbf{8 0}$ 903-914.

Miller M, Kawabata S, Wiltshire-Clement M, Reventos J \& Gordon JW 1993 Increased vasopressin secretion and release in mice transgenic for the rat arginine vasopressin gene. Neuroendocrinology 57 621-625.

Morris BJ 1993 Control of receptor sensitivity at the mRNA level. Molecular Neurobiology 7 189-205.

Murase T, Ecelbarger CA, Baker EA, Tian Y, Knepper MA \& Verbalis JG 1999 Kidney aquaporin-2 expression during escape from antidiuresis is not related to plasma or tissue osmolality. Journal of the American Society of Nephrology 10 2067-2075.

Murphy D, Bishop A, Rindi G, Murphy MN, Stamp GW, Hanson J, Polak JM \& Hogan B 1987 Mice transgenic for a vasopressin-SV40 hybrid oncogene develop tumors of the endocrine pancreas and the anterior pituitary. A possible model for human multiple endocrine neoplasia type 1. American Journal of Pathology 129 552-566.

Musabayane CT, Brimble MJ \& Balment RJ 1985 Renal sodium retention and vasopressin induced kaliuresis in ethanol anaesthetised rats. Acta Endocrinologica 110 214-220.

Nagasaki H, Yokoi H, Arima H, Hirabayashi M, Ishizaki S, Tachikawa K, Murase T, Miura Y \& Oiso Y 2002 Overexpression of vasopressin in the rat transgenic for the metallothioneinvasopressin fusion gene. Journal of Endocrinology 173 35-44.

Oiso Y, Iwasaki Y, Kondo K, Takatsuki K \& Tomita A 1988 Effect of the opioid kappa-receptor agonist U50488H on the secretion of arginine vasopressin. Study on the mechanism of U50488H-induced diuresis. Neuroendocrinology 48 658-662.

Ostrowski NL, Lolait SJ, Bradley DJ, O'Carroll AM, Brownstein MJ \& Young WS III 1992 Distribution of V1a and V2 vasopressin receptor messenger ribonucleic acids in rat liver, kidney, pituitary and brain. Endocrinology 131 533-535.

Pfeiffer R, Kirsch J \& Fahrenholz F 1998 Agonist and antagonist-dependent internalization of the human vasopressin V2 receptor. Experimental Cell Research 244 327-339.

Schmale H \& Richter D 1984 Single base deletion in the vasopressin gene is the cause of diabetes insipidus in Brattleboro rats. Nature 308 705-709.

Stoehr JD, Cheng SW \& North WG 1993 Homozygous Brattleboro rats display attenuated conditioned freezing responses. Neuroscience Letters 153 103-106.

Terashima Y, Kondo K, Mizuno Y, Iwasaki Y \& Oiso Y 1998 Influence of acute elevation of plasma AVP level on rat vasopressin V2 receptor and aquaporin-2 mRNA expression. Journal of Molecular Endocrinology 20 281-285.

Terashima Y, Kondo K \& Oiso Y 1999 Administration of oxytocin affects vasopressin $\mathrm{V} 2$ receptor and aquaporin-2 gene expression in the rat. Life Sciences 64 1447-1453. 
Tian Y, Sandberg K, Murase T, Baker EA, Speth RC \& Verbalis JG 2000 Vasopressin V2 receptor binding is down-regulated during renal escape from vasopressin-induced antidiuresis. Endocrinology 141 307-314.

Valtin H, Schroeder HA, Benirschke K \& Sokol HW 1962 Familial hypothalamic diabetes inspidus in rats. Nature $\mathbf{1 9 6}$ 1109-1110.

Verbalis JG 1984 An experimental model of syndrome of inappropriate antidiuretic hormone secretion in the rat. American Journal of Physiology 247 E540-E553.

Verbalis JG 1994 Pathogenesis of hyponatremia in an experimental model of the syndrome of inappropriate antidiuresis. American Journal of Physiology 267 R1617-R1625.

Verbalis JG \& Drutarosky MD 1988 Adaptation to chronic hypoosmolality in rats. Kidney International 34 351-360.

Waller S, Fairhall KM, Xu J, Robinson IC \& Murphy D 1996 Neurohypophyseal and fluid homeostasis in transgenic rats expressing a tagged rat vasopressin prepropeptide in hypothalamic neurons. Endocrinology 137 5068-5077.

Walter SJ, Tennakoon V, McClune JA \& Shirley DG 1996 Role of volume status in vasopressin-induced natriuresis: studies in Brattleboro rats. Journal of Endocrinology 151 49-54.

Woods RL \& Johnston CI 1983 Contribution of vasopressin to the maintenance of blood pressure during dehydration. American Journal of Physiology 245 F615-F621.

Yamamura Y, Ogawa H, Yamashita H, Chihara T, Miyamoto H, Nakamura S, Onogawa T, Yamashita T, Hosokawa T, Mori T et al. 1992 Characterization of a novel aquaretic agent, OPC-31260, as an orally effective, nonpeptide vasopressin V2 receptor antagonist. British Journal of Pharmacology 105 787-791.

Received 8 October 2001

Accepted 19 December 2001 